Vol.7, No 1. Diciembre de 2015 pp. 74 -93

Recibido para publicación: octubre 2 de 2015

Aceptado para publicación: noviembre 16 de 2015

\title{
EL OUTSOURCING COMO NUEVA FORMA DE RELACION DE TRABAJO Y SUS IMPLICACIONES LABORALES
}

\section{Outsourcing as a new way the relationship work and labour implications}

\author{
Autores: Georgina De León Vargas ${ }^{1}$ \\ Correspondencia: georgina.deleon@curnvirtual.edu.co
}

\begin{abstract}
RESUMEN
El presente artículo de investigación tiene como objeto determinar cuáles son las implicaciones jurídicas del Outsourcing como nueva forma de relación laboral en México y en Sudamerica. Así pues, para estos fines se esbozará que a finales de los 80 s y principio de los 90 s comenzó a consolidarse el Outsorcing como un proceso en el que se realiza una contratación de empresa a otra para la realización de tareas específicas, así estás podrían generar mayor productividad encargándose de su actividad principal, lo que ha representado utilidades para las empresas que usan esta modalidad, pero a la vez con el aumento de esta se han visto afectados algunos de los derechos laborales de los trabajadores de estas empresas prestadoras de servicios específicos.
\end{abstract}

Palabras Claves

Outsourcing, Laboral, Sistema, Intermediación, Implicaciones

\begin{abstract}
The object of this study is to determine what are the judicial implications of outsourcing as a new type of work relationship in Mexico, then we will comment that In the late 80's and early 90's outsourcing started to consolidate as a business practice in which companies would hire other business to handle a specific task. In order to, generate an increase in productivity letting companies to focus on their main activity of revenue, thus increasing utilities for the business that employ this modality. Nonetheless, this increase in productivity also has affected labour rights for the workers of this companies that deal on specific services.
\end{abstract}

\section{Keywords}

Outsourcing, labour, Sistem, Intermediation, Implications

\footnotetext{
${ }^{1}$ Abogada. Magister en Derecho del trabajo (Laboral) de la Universidad Autónoma de Guerrero México. Docente Programa de Derecho Cartagena de la Corporación Universitaria Rafael Núñez.
} 


\section{INTRODUCCIÓN}

Desde hace algunos años se ha puesto de moda un sistema, propiciado por empresarios, sindicatos corporativos y la venia no tan remota de las autoridades laborales, mediante el cual una autodenominada "empresa de administración de personal" celebra contratos de arrendamiento con un patrón cualquiera y pone a su disposición a los trabajadores que necesite, garantizando confianza, conocido esto como Outsourcing dicho en otras palabras; una empresa delega a otra empresa la ejecución de una serie de servicios que anteriormente asumía directamente a través de sus propios empleados.

Rothery (2010) dice que el Outsourcing es la contratación a largo plazo de procesos de un proveedor externo para conseguir mayor efectividad se trata de un crecimiento basado en la capacidad de concentrarse en aquellas áreas que contribuyen de manera directa al éxito de la compañía, a fin de que ésta sea reconocida en los mercados y ofrezca productos o servicios con el sello de la excelencia.

Entre sus ventajas encontramos, la empresa delega responsabilidades en el momento de contratar por Outsourcing, ganando tiempo para concentrarse en actividades centrales. Los costos de actualización tecnológica son asumidos por el contratista, los contratistas se ven en la obligación de crear estándares de calidad al más alto nivel, convirtiendo al contratante en usuario de ellos sin el costo en el que debería incurrir para llegar a dichos estándares de manera individual (Rothery, 2010). 
Otra ventaja importante es la posibilidad de compartir los riesgos de determinada operación con el contratista, lo que implica que un error o fracaso en la orientación dada por la compañía contratista no será asumida en su totalidad por el empresario.

La importancia de poder compartir los riesgos, está en la relación tan cercana que surge entre contratante y contratista ya que ambos tienen la necesidad y el compromiso de ser exitosos, por otro lado también permite aumentar la inversión de capital en las áreas centrales de la empresa.

Si se nombran las ventajas estaría obligada a nombrar las desventajas de esta figura las cuales son la pérdida de control de la compañía sobre las operaciones o servicios contratados por Outsourcing (Rothery, 2010).

También se habla de una posible inestabilidad en la relación de trabajo entre contratista y contratante, por los cambios que la compañía contratante haga de sus gerentes o personal de apoyo aplica al trabajador para que éste no acumule una antigüedad laboral y las prestaciones económicas más importantes que debe recibir por ley, como por ejemplo el reparto de utilidades, subsidios por antigüedad, derechos de jubilación, etc.

En la legislación Mexicana se hace posible su implementación básicamente a través de tres figuras jurídicas que son: las empresas asociativas de trabajo, las cooperativas de trabajo asociado, y la contratación independiente.

La práctica de Outsourcing se ha llevado a cabo desde hace pocos años, lo que ha desencadenado el desconocimiento de este tipo de servicios en México. Recientemente, el tema se ha dado a conocer en el mercado local, debido a que muchas firmas profesionales lo han implementado dentro de los servicios de negocios que les ofrecen a sus clientes, y muchas de esas compañías o firmas se 
han dado cuenta de que a través de esta práctica se pueden obtener varias ventajas, principalmente, la búsqueda de mayor especialización.

El Outsourcing es un instrumento jurídico laboral "ilegalmente legal”, a mi modo de ver porque el asunto está en darle al empleado ¿por tiempo indefinido? contratos de trabajo eventuales con las prestaciones mínimas de Ley, pero liquidándolo inmediatamente después de finalizar cada contrato, el trabajador puede estar años laborando y jamás acumular derechos laborales legales, incluso existe el "Outsourcing" en las dependencias públicas de los gobiernos locales, estatales o federales y permiten esta ilegalidad, hay casos que han copiado este mal ejemplo como el de la Secretaria del Medio Ambiente del Gobierno del Distrito Federal donde a sus trabajadores eventuales "se les interrumpe por dos días la vigencia de sus contratos de trabajo para que no acumulen ningún derecho laboral” ,por ejemplo, en un mes de treinta días únicamente se da a la vigencia del contrato de trabajo sólo veintiocho días, se da una interrupción de la relación laboral por dos días y nuevamente se le vuelve a contratar el día primero del siguiente mes con el mismo procedimiento desleal y perjudicial para el derecho social (Pérez, 1995), he aquí donde se cuestiona la efectividad de la ley federal del trabajo o mejor de los legisladores que no han presentado reformas eficaces para impedir que cosas como estas entorpezcan la finalidad de su creación como lo es apoyar el progreso de la economía nacional la elevación de las condiciones de vida de los trabajadores ya que el derecho al trabajo constituye una unidad indisoluble pues todos sus principios e instituciones tienden a una misma función que es la regulación armónica y justa de las relaciones entre el capital y el trabajador.

Sin duda, se sabe que resulta onerosa la creación de empleos y que las acciones fiscales de las autoridades tienen una consigna recaudatoria, no de espíritu o solidaridad empresarial; de ahí se parte para definir el costo real de un trabajador que incluye: Salario, Seguridad social, Créditos fiscales. Impuesto a la 
nómina, INFONAVIT, SAR, Prestaciones sindicales, Costos de sindicato, Costos de previsión social, como son vales de despensa, becas, actividades culturales y deportivas, etc.

El costo de un puesto de trabajo depende además de otros factores, de otros costos como el costo de inversión productiva, el costo sindical que incluye sindicatos onerosos como el petroquímico y el farmacéutico, el costo de la zona, es decir, si existe conflictividad laboral ahí existe un costo de no infiltración, el costo ambiental, los costos de previsión social cuando todas las prestaciones son parte de las cláusulas de los contratos colectivos de trabajo y no pagarlas serían violaciones al contrato y por lo tanto sujetas al estallamiento de una huelga.

Los costos de creación de un empleo incluyen: los costos de la inversión productiva, los costos básicos laborales, los costos no salariales, los costos de despido, los costos de selección de personal y los costos de la administración jurídica laboral. Estos costos representan para el sector privado una erogación de casi 60 por ciento más del salario acordado e incluye: seguro de riesgos de trabajo, enfermedades y maternidad, cuota fija social, cuota adicional a salarios con más de 3 SMG, pensionados y sus beneficiarios, prestaciones en dinero, seguro de invalidez y vida, guarderías y prestaciones sociales, retiro, cesantía en edad avanzada y vejez, INFONAVIT, impuesto a la nómina y otros costos como aguinaldos, vacaciones, prima vacacional, liquidaciones, etc. Todo esto representa el 59.26 por ciento. Por estos costos que le generan a los empleadores un trabajador contratado formalmente hace que ellos prefieran contratarlos mediante la figura del Outsourcing, la cual evidentemente reduce estos costos (Pérez, 1995).

La presente investigación trata de abordar el gran y confuso tema de EL OUTSOURCING COMO NUEVA FORMA DE RELACION DE TRABAJO Y SUS IMPLICACIONES LABORALES, resolviendo el siguiente interrogante ¿El 
Outsourcing como nueva forma de relación laboral se integra al modelo de

Derecho social proteccionista que se contempla en todo el cuerpo de la Ley Federal del Trabajo y si realmente la reforma laboral actual cubre con las expectativas para detener las repercusiones de este modelo de contratación laboral?.

\section{MÉTODOS}

El presente es un estudio de tipo deductivo, trasversal, comparativo, descriptivo, utilizando un tipo metodológico la cual emplea el método cualitativo.

Según el criterio del maestro Sampieri la investigación es transversal cuando se recolecta datos en un solo momento, en un tiempo único, siendo su propósito describir y analizar su incidencia e interrelación en un momento dado.

Es de tipo descriptivo ya que mediante este tipo de investigación que utiliza el método de análisis se logra caracterizar un objeto de estudio o una situación concreta, señala sus características y propiedades además puede servir de base para investigaciones que requieren un mayor nivel de profundidad.

Enfoque cualitativo: Es el procedimiento metodológico que utiliza palabras, textos, discursos dibujos, gráficos e imágenes para comprender la visión social por medio de significados y desde una perspectiva holística, pues se trata de entender el conjunto de cualidades interrelacionadas que caracterizan a un determinado fenómeno, esta clase de investigación utiliza datos cualitativos como las palabras, textos, dibujos, gráficos e imágenes, utiliza descripciones detalladas de hechos, citas directas del habla de las personas y extractos de pasajes enteros de documentos para construir un conocimiento de la realidad social, en un proceso de conquista-construcción-comprobación, teórica. 
Instrumentos de recolección de datos: Los instrumentos mediante el cual se obtuvo la información para llevar a cabo la presente investigación son las siguientes: observación directa; es una técnica que consiste en observar atentamente el fenómeno, hecho o caso, tomar información y registrarla para su posterior análisis la observación es un elemento fundamental de todo proceso investigativo, en ella se apoya el investigador para obtener el mayor número datos, gran parte del acervo de conocimientos que constituye la eficiencia ha sido lograda mediante la observación.

\section{RESULTADOS Y DISCUSIÓN}

\section{Antecedentes De Outsourcing}

Al comienzo de la era post-industrial se inicia la competencia en los mercados globales y es entonces cuando las empresas deciden que otros asumen responsabilidades, porque no parecía suficiente su capacidad de servicios, la verdad es que siempre se ha hecho Outsourcing pero con una concepción distinta a la que hoy se conoce. Después de la segunda guerra mundial, las empresas trataron de concentrar en sí mismas la mayor cantidad posible de actividades, para no tener que depender de los proveedores, sin embargo esta estrategia que en principio resultara efectiva fue haciéndose obsoleta con el desarrollo de la tecnología ya que nunca los departamentos de una empresa podían mantenerse tan actualizados y competitivos, pero realmente el concepto de Outsourcing comienza a generar credibilidad al inicio de la década de los 70 s sobre todo en las áreas de informática, tecnologías las primeras empresas que implementaron modelos de Outsourcing fue la Price Waterhouse (Instituto Mexicano de Contadores Públicos. [I.M.C.P.], 2014)

Como se dijo arriba a mediados del siglo pasado, al finalizar la segunda guerra mundial las empresas trataron de llevar a cabo con personal propio la mayor cantidad de actividades posibles, con la intención de no depender de las 
Vol.7, No 1. Diciembre de 2015 pp. $74-93$

políticas y prácticas de los distintos proveedores. En un principio esta estrategia resulto efectiva; sin embargo, con el paso del tiempo, la tecnología se desarrolló cada vez más y trajo como consecuencia que los distintos departamentos de una empresa no pudieran mantenerse actualizados. Adicionalmente, la capacidad de servicio con la que contaban para acompañar su estrategia de crecimiento resultaba insuficiente, situación que se traducía en la pérdida de competitividad.

Las agencias independientes especializadas no padecían los impactos de avances tecnológicos, pues al contar con un menor número de operaciones, podían enfocarse en mantenerse a la vanguardia dentro de sus respectivos campos de acción, volviéndose cada vez más competitivos.

Al principio de los años sesenta, las empresas observaron que los proveedores externos tenían una mejor asignación de recursos técnicos y humanos, por lo que comenzaban a realizar contratos de gestión de activos referidos al procesamiento de datos, para responder a la necesidad de obtener un mayor beneficio de los sistemas computacionales crecientes.

Esta palabra que es un anglicismo comenzó a escucharse en América latina al terminar la década de los ochentas e iniciarse los primeros años noventa. Los especialistas en la materia, especialmente en relaciones industriales, fueron los primeros en tratar de desentrañar este fenómeno como ya se ha dicho proveniente de los estados unidos, y como es usual en los casos del surgimiento de las nuevas realidades, los juristas trataron de comprenderlo mediante el uso de figuras ya conocidas como la intermediación (Ackerman et al., 2011)

Si se analizan las obras de derecho del trabajo que se publicaron en esos años, se podrá claramente apreciar que la preocupación de los juristas y tratadistas se centraba en la flexibilidad laboral, que se reclamaba como fruto del predominio de las ideas neo-liberales, impulsadas por el congreso de Washington, y que el tema de la descentralización productiva de las empresas, y sus secuelas sobre el mundo del trabajo asalariado, solo se manifestaba con un estudio del contrato de trabajo, campo en el cual comenzaron a examinarse las denominadas 
relaciones atípicas del trabajo, dentro de las cuales se manifestaba con predominio la conexión triangular, expresada por un trabajador contratado por un empleador cuyos servicios eran utilizados por un tercero.

\section{Antecedentes del outsourcing en mexico.}

En México, a mediados del siglo pasado, una parte del sector empresarial visualizó la necesidad y conveniencia de recurrir a servicios externos y especializados para minimizar las amenazas laborales, así como para ahorrar tiempo y dinero en el manejo de nómina, sus cargas financieras y aspectos legales. Sin embargo es hasta la década de los noventa cuando el Outsourcing comienza a proliferar entre varios grupos o consorcios empresariales y aparecen las empresas de servicios corporativos, con el objeto de proporcionar servicios a diferentes empresas de un mismo dueño o grupo empresarial. Estas entidades se distinguen por no generar utilidades, constituyendo por lo general Sociedades Civiles (Díaz, 1997).

Entonces si echamos un vistazo a la historia de esta figura en México llegamos a la conclusión que es relativamente nueva, si toca datarla se remontaría a los años cuarenta, cuando las compañías contrataban los servicios de vigilancia y limpieza de otras empresas, más tarde los de comedor y mantenimiento, casi hasta llegar a nuestros días al área de reclutamiento y selección del personal de la empresa. En la década de los 90s la corriente organizacional ha cambiado a la reubicación de recursos y servicios que permitan la especialización de los negocios.

Al tomar en cuenta esto se establecen las políticas del mercado de trabajo, las cuales son un conjunto de instrumentos y programas, por medio de los cuales el sector público interviene con la intención de combatir o evitar el desempleo, mitigar sus efectos y apoyar a la población activa en riesgos de desocupación (I.M.C.P., 1997), por medio de estas políticas se pretendió fortalecer el enlace entre empleados y puestos de trabajo, contribuir a solventar los costos de la 
Vol.7, No 1. Diciembre de 2015 pp. $74-93$

búsqueda, colaborar al mejoramiento de las habilidades de los desempleados y apoyar directamente o indirectamente la creación de fuentes de trabajo o el mantenimiento de las existencias, esto es lo que en teoría vino hacer el Outsourcing en México, pero en la realidad lo que vemos es otra cosa, constantes abusos de parte de las empresas contratistas para con sus trabajadores, puesto que como se analizará más adelante, los trabajadores pierden muchos derechos laborales al ser vinculados mediante esta figura y todo por la necesidad que tienen de un sustento diario para sus familias y se dejan menoscabar esos derechos que la ley y el tiempo nos han reconocido.

En México, como en otros países las políticas de mercado de trabajo son un importante instrumento de estrategia económica y social. Durante la última década se destinó un monto considerable de recursos, públicos para aliviar la pérdida de ingresos por desempleo, mejorar las habilidades de la fuerza de trabajo desocupada y facilitar el encuentro cuantitativo y cualitativo entre oferta $y$ demanda.

Así en los últimos años estas políticas abarcan prácticamente todas las modalidades en que se suelen presentar: Intermediación. Capacitación. Creación directa o indirecta de empleos.

A diferencia de lo que sucede en la mayoría de los países desarrollados se carece de la vertiente orientada al seguro de desempleo, rubro en el cual solo existe una política incipiente en la capital mexicana. Durante la última década del siglo pasado, estos programas se transforman; dejan de ser esquemas piloto y se convierten en programas de cobertura nacional, dotados de una estructura más compleja que rebasa el marco federal, para apoyarse en instrumentos de carácter estatal y municipal. 


\section{Situación Actual de la Intermediación Laboral en México.}

En México, la demanda de servicios de administración de personal mediante la tercerización ha venido en aumento, lo que provoca, por inercia, un aumento en el mercado de estas formas de empleo. Como consecuencia de considerar redituable esta estrategia empresarial, surgen diversas prácticas que en ocasiones distan de la seriedad y calidad requeridas.

Las prácticas de tercerización de personal denominadas no serias, ocasionan que algunas empresas utilicen esta forma para su conveniencia, con efectos negativos para la economía nacional y, obviamente, para el empleado.

Dentro de estos esquemas se encuentran las empresas que se disfrazan de sociedades cooperativas y consideran al trabajador falsamente como socio; las que evitan el pago de cuotas obrero-patronales, ya sea por no inscribir ante el Seguro Social o afiliando al empleado con un salario menor al real, llegando en ocasiones a registrarlo con el monto mínimo permitido; otras tantas que sustituyen el pago de un salario a los trabajadores por remuneración por vía de honorarios. También existe la figura de no generación de utilidades, mediante la instauración de una empresa que solo contrate al personal y otras que se manejan al borde de la legalidad o en ocasiones totalmente ilícitas.

Debido a este tipo de prácticas se generaliza a las empresas de tercerización de personal como entidades que defraudan por igual a los trabajadores y empresarios, o como opciones carentes de seriedad ante los ojos de diversos sectores, como el empresarial y el público, incluso, entre los mismos trabajadores.

En este sentido es conveniente evaluar los pros y los contras al tercerizar cualquier servicio dentro de una organización, para que la reputación de las compañías no sea afectada por situaciones ajenas a su filosofía empresarial. 
La inserción de las empresas en el mercado internacional y la globalización dan como resultado que grandes compañías, incluso pequeñas adopten la tercerización del recurso humano como un camino no solamente para obtener ahorros administrativos, sino como nueva forma de relaciones laborales ante un entorno global altamente competitivo.

En el caso particular de México, se tiene registro de que en los últimos tres años, $40 \%$ de las nuevas altas en el Seguro Social se realizaron por la intermediación; asimismo, se estima que alrededor de 105 mil empleados están contratados en el país bajo ese esquema, y que en promedio se inscribe un millón de contrataciones por intermediación al año (AMECE-GS1 \& Accenture, 2011). La tercerización convive con la actual ley Laboral al reconocer que antes de la más reciente reforma en la LSS, se abusó del uso de la intermediación como forma de ahorro y hasta evasión del pago de cuotas del IMSS y prestaciones que marcan la ley. En la actualidad es más difícil evadir la responsabilidad, incluso dicha reforma coadyuvó para frenar la proliferación de empresas prestadoras de intermediación que promovían estas prácticas ilegales (Rivo, 2000).

Los sectores que más usan la tercerización son: servicios, tecnología de la información, manufactura de valor agregado, maquiladoras y recientemente se migró, casi en su totalidad, del departamento de recursos humanos a las empresas prestadoras de este servicio; permeando así en los campos financieros, de tecnología, logística, pero no hacia otros segmentos donde todavía es incipiente.

Para el año 2009, a pesar de la crisis económica mundial, se registró un incremento en los servicios de intermediación de 10\%. En este contexto México representa un mercado de 3 mil 200 millones de dólares en exportación de software e intermediación, detrás de India con una facturación de 20 mil millones y Filipinas con 7 mil según cifras de la consultora México IT. En la actualidad las empresas solicitan una variedad de servicios que van desde el mantenimiento y desarrollo de sistemas, hasta la administración informática de la entidad, siendo 
esta última la que presentó mayor crecimiento durante dicho año (López et al, 2009).

Al estudio "la alta dirección en México frente al reto de la innovación" elaborado por AMECE-GS1 México y Accenture (2011), en el que participaron 150 directivos mexicanos, arroja los siguientes resultados: $26 \%$ de los encuestados señalan que su empresa incrementará el volumen de las operaciones de tercerización, 57\% conservará su nivel actual. 9\% tiene intención de reducir su inversión de intermediación. $8 \%$ no utiliza ese servicio o está considerando eliminarlo (Rueda, 1999).

De manera general estos servicios son utilizados por los grandes corporativos; no obstantes que, las PyMES también pueden resultar beneficiadas. Estas ventajas se traducen en reducción de costos al acceder a economías compartidas, donde el proveedor les renta licencias de software $u$ otras aplicaciones, a menor precio (Díaz, 1997).

\section{Datos Estadísticos de la Intermediación En México.}

Según datos estadísticos del INEGI esta figura en México y de acuerdo con los resultados del Censo Económico 2010 del INEGI, el suministro de personal por otras empresas para realizar actividades productivas se refleja especialmente en los corporativos, donde el $48.6 \%$ del personal es subcontratado; en servicios financieros y de seguros alcanza $42.6 \%$, y en servicios de información en medios masivos es de 35.3\%. Según el censo, a escala nacional la contratación mediante la práctica de tercerización abarca $13.6 \%$ de los trabajadores; es decir, estas empresas proveen del personal que se subcontrata a otras compañías por tipo de contratación, el INEGI descubrió que 29.8\% de las personas que trabajan son propietarios, familiares y trabajadores que reciben remuneración; $56.6 \%$ es personal remunerado que recibe un sueldo o salario; y 13.6\% restante representa a empleados subcontratados mediante tercerización. 
A partir de la información obtenida en la Encuesta Nacional de Empleo y Seguridad Social (ENSS) de 2004, referente al número de trabajadores que tenían un contrato temporal y no contaban con prestaciones de seguridad social (excluyendo a los trabajadores del campo y de la construcción), se determinó que proporción representa este grupo de trabajadores con respecto a la población económicamente activa (PEA) considerándose ésta última como base para proyectar al total de trabajadores contratados bajo esquema de tercerización, asumiendo que dicha razón se mantendrá constante respecto durante el periodo 2009-2030 (Consejo Nacional de Población [CONAPO], 2004).

Con este supuesto se proyectó la población de trabajadores por edad y sexo, los resultados en promedio se estima que durante el periodo 2009-2030 habrá 1.9 millones de trabajadores contratados bajo este esquema, sin derecho a prestaciones de seguridad social; de los cuales 1.1 millones serán hombres y 800 mil mujeres, constituyéndose estos como el grupo poblacional a partir del cual se realizó la estimación de ingresos y gastos para el SEM, bajo el supuesto de que las reformas a la LSS, anteriormente descritas sean aprobadas y con ello las empresas que prestan servicios de personal mediante la tercerización, afilien a sus trabajadores al IMSS (CONAPO, 2004). (Ver anexo 3).

Por otro lado la Asociación Mexicana de Empresas de Capital Humano (AMECH) realiza estudios sobre el empleo permanente y temporal, tanto en México como a nivel mundial, así como estudios sobre legislación vigente y propuestas para estas materias algunos artículos destacan lo siguiente: las necesidades del personal que tienen en las empresas como consecuencias de las eventualidades surgidas en múltiples áreas de actividad, suelen convertirse a menudo en una clara oportunidad de empleo para los trabajadores con dificultad de introducción en el mercado laboral. 
Una empresa de personal temporal (EPT) es aquella que gestiona las necesidades de empleo provisional que tienen sistemáticamente las compañías usuarias. Estas compañías simplifican a la empresa usuaria la gestión de búsqueda y selección del trabajador idóneo, sin asumir los riesgos que ello implica, ya que la selección y formación de los mismos, correrá a cargo de la EPT, quien además de hacer que la compañía cambie costos fijos por variables, dispone de los servicios completos que aseguran una buena relación calidad de servicio-riesgos. (Ver anexo 4).

En México se establece que solo el $20 \%$ de las personas contratadas bajo este esquema, se les ofrece la certeza de que los patrones cumplen con sus obligaciones fiscales. Lo anterior se traduce en diversos problemas; uno de ellos es la recaudación de cuotas que impacta directamente en el aparato financiero del IMSS. Basta mencionar que en 2008, el IMSS dejó de captar alrededor del 30\% de su potencial recaudable.

Por otro lado, el SAT ha sufrido una afectación en materia de impuestos sobre la renta (ISR) de aproximadamente 3 mil 800 millones de pesos en los últimos dos años sin considerar el impuesto al Valor Agregado (IVA) que los contribuyentes acreditan en estos modelos. (Ver anexo 5)

Durante los últimos dos años se detectaron 688 casos de sociedades simuladas; se trabajaron 25 asuntos como casos penales, de los cuales siete ya están en los juzgados; ocho se presentaron ante el Ministerio Público; dos están en la procuraduría Fiscal de la Federación, y ocho expedientes se encuentran en proceso de integración. Derivado de la situación anterior se determinaron créditos fiscales con un monto de 15 mil millones de pesos, de los que solo se han recuperado 340 millones (Risco, 2010). 
Hoy en día existen alrededor de 4 millones de personas desempeñándose bajo el sistema de tercerización, lo cual afecta aproximadamente a 230 mil trabajadores que pierden acceso a los servicios de salud, pensiones, guarderías y créditos para vivienda. El tema comienza hacer preocupante, pues en 2007 la Secretaria del Trabajo y Previsión Social (STPS) reportó que México ocupaba el lugar decimonoveno a nivel mundial, con 2.4 millones de personas laborando bajo esa modalidad; sin embargo, la crisis económica de 2008 y 2009 propició un incremento de $4.6 \%$, convirtiendo a la tercerización en el único servicio que creció durante esa etapa. (Ver anexo 6).

\section{CONCLUSIONES}

Los esquemas comerciales son dinámicos por ello una constante trasformación, las culturas se mezclan y evolucionan, recogiendo conceptos y formas de vida de distintas sociedades. El intercambio y la apertura de prácticamente todos los países, han tenido efectos en la forma en que se llevan a cabo las relaciones laborales, por lo que surgen opciones distintas a la tradicional; es decir, aquella que reconoce lisa y llanamente la existencia de un patrón que se beneficia de los servicios de su trabajador, por lo cual retribuye directamente con un salario.

Pero los tiempos modernos ese dinamismo del que hemos venido hablando le da paso al reconocimiento de la existencia del trabajo a distancia, de tiempo parcial, con pago por horas, incluso el incremento de los llamados freelance que son lo mismo que trabajadores independientes, todos estos conceptos se han venido incorporando a nuestro lenguaje actual y a la vida económica y por supuesto han sido objeto de estudios por diferentes tratadistas e investigadores aficionados. 
Sin dejar atrás la forma de relación laboral, referida como Outsourcing de personal que en la actualidad podemos afirmar que es una modalidad globalizada que de manera general ha mostrado tener un alto impacto tanto como positivo y negativo, positivo para las empresas y negativo por supuesto para los trabajadores, cuando afirmamos que es positivo para las empresas nos estamos refiriendo a que los recursos materiales, financieros y humanos son destinados al objeto principal de la empresa, sin requerir distraerse en otras áreas, se debe afirmar que estos cambios no solo inciden de manera personal para la empresa si no también inciden a nivel social por lo que no es solo aspectos financieros el que ha de tomarse en cuenta para evaluar la tercerización, sino por supuesto los efectos que tendrán en sus relaciones con los trabajadores y en el cumplimiento de las diversas legislaciones que de dicha relación emane.

Es por ello que México incorporó en su legislación esta figura en su actual reforma a la Ley Federal del Trabajo, para adecuar los textos normativos a su realidad económica y por supuesto social, es así que los principales cambios efectuados son aquellos que pretenden el mantenimiento del equilibrio entre el capital y la fuerza de trabajo.

En México, la tercerización o subcontratación de los servicios de personal no solo trae consigo ventajas para la forma de realizar actividades en las empresas, sino que se presta para el uso indebido de esta figura, la cual deja a los trabajadores fuera de los derechos sociales que la propia Constitución les ha otorgado de manera irrenunciable a través de la historia como resultado del derramamiento de sangre de hombres valientes que lucharon contra la opresión y la desigualdad social. Ante esto, el Estado realiza modificaciones a la legislación con el fin de reducir las lagunas que dieron pauta al uso indebido, y en el mismo tenor, ha intensificado las labores de fiscalización mediante programas coordinados entre las diversas autoridades afectadas (laborales, fiscales y de seguridad social), detectando una alta evasión fiscal y un perjuicio social, de igual 
Vol.7, No 1. Diciembre de 2015 pp. $74-93$

magnitud para los empleados contratados mediante Outsourcing, debido al nulo 0 reducido acceso que tienen a las prestaciones de servicio médico y económicas, como las incapacidades y la posibilidad de obtener una pensión en el futuro.

Con la disgregación de la empresa, con la externalización del trabajo, se pierde una serie de garantías y estabilidades que transforman la calidad del trabajo, volviéndolo precario e inseguro, ya que los trabajadores externalizados tienen una condición más precaria que los trabajadores internos o de la gran empresa, estos trabajadores, es decir, los externos sufren la desigualdad entre los trabajadores situados al interior de la empresa, propiciando esto aún desequilibrio entre trabajadores integrados al mismo proceso productivo, excluyendo a una parte de ellos de su protección.

Cabe resaltar que ante los actos de evasión, no solo son los trabajadores los afectados, sino también las empresas que contrataron los servicios de terceros, ya que impacta negativamente en sus finanzas al tener que, con motivo de legislación laboral y fiscal, reconocer en su carácter de responsable solidario, pasivos laborales y fiscales que sin duda, superan los beneficios obtenidos al optar por la figura del Outsourcing indebido.

Lo anterior no significa que se debe ver al Outsourcing como un mecanismo o figura negativa, por el contrario debe implicar para las empresas una correcta evaluación, seguimiento y control de los servicios que ha contratado, es decir, se debe efectuar este tipo de contrataciones con empresas que estén sólidas y cumplan cabalmente con todas las obligaciones fiscales y laborales, y tener mucho cuidado con las innumerables empresas patitos que hoy día existen que lo que hacen es estafar tanto al trabajador como a la empresa que los contrata.

El Outsourcing en su versión autentica no genera problemas jurídicos, económicos ni sociales; se trata de empresas formalmente constituidas, con 
oficinas y talleres propios, que asumen a plenitud sus obligaciones y son empleadores directos de sus propios trabajadores.

La figura del Outsourcing evidentemente deja a los trabajadores sin sus derechos y beneficios laborales, cuando es usada de manera ilegal o abusiva.

\section{REFERENCIAS.}

Rothery, b., robertson, I.( 2010) Outsourcing La subcontratación. U.S.A. Limusa

Pérez j. (1995) Outsourcing una alternativa en expansión. Revista del Instituto Peruano de Administración de Empresas. Perú. Noviembre-Diciembre de 1995., p. 42.

Comisión Representativa Ante Organismos De Seguridad Social [CROSS]. (2014) Outsourcing Prestación de servicios de personal y sus implicaciones en materia de seguridad social 2a edición. Instituto Mexicano de Contadores Públicos. [I.M.C.P]. México.

Ackerman, Albuquerque, De buen, Giglio, Melgar, Morgado, Valenzuela, Murgas Torranzza, Pasco Cosmópolis, Raso Delgue "Grupo de Los Nueve" (2011). El Outsourcing Visión Iberoamericana, Edit., Porrúa, México.

Díaz, j. (seminario mayo 1997 con el. Título) externalización de actividades: un paso más alla de la subcontratación"). "el outsourclng. Antesala de la empresa virtual".

Instituto Mexicano De Contadores Públicos (2011) Prestación de Servicios de Personal $Y$ sus implicaciones en materia de Seguridad Social. Colección Fiscal. Outsourcing, Colegio de Contadores de México. I.M.C.P. 


\section{Vol.7, No 1. Diciembre de 2015 pp. 74 -93}

- AMECE-GS1, México., (2011) Accenture. La Alta Dirección en México frente al Reto de la Innovación, México.

Rivo, E. (2000) Externalización más allá de la concentración, Edit, Vigo, Universidad de Vigo, España, Pág. 34

López, A., Ramos, D. \& Torre, I. (2009) Las exportaciones de servicios de América Latina y su integración en las cadenas globales de valor. Comisión Económica para América Latina y el Caribe (CEPAL). Colección Documentos de proyectos. Recuperado de : http://www.cepal.org/publicaciones/xml/3/35963/docw37fin.pdf

Rueda, J. (1999.) Intermediación, de la táctica a la iniciativa Estratégica, México, pág. 82-92. edit, Porrúa

Consejo Nacional de Población (CONAPO), Coordinación de Administración de Riesgos Profesionales Encuesta Nacional de Empleo y Seguridad Social (ENSS) 2004, Proyección de la PEA 2000-2050.

Risco, J. (2010) Estudio Comisionado a Mckinsey y Co, por parte del CIETT., México 